\title{
Elevated Human Chorionic Gonadotrophin Due to Pancreatic Cancer
}

\author{
Asha Manohar ${ }^{1}$, Erika Werner ${ }^{2}$, Jamie Murphy ${ }^{1}$ \\ ${ }^{1}$ Anesthesia and Critical Care Medicine, The Johns Hopkins Hospital, Baltimore, USA; ${ }^{2}$ Department of Gynecology and Obstetrics, \\ The Johns Hopkins Hospital, Baltimore, USA. \\ Email: amanoha2@jhmi.edu
}

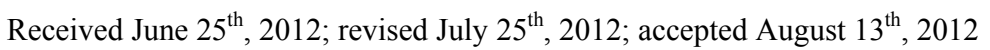

\begin{abstract}
Preoperative pregnancy testing is common practice among anesthesiologists. Little is re-ported in anesthesia literature on causes other than pregnancy for elevated human chorionic go-nadotrophin (hCG) levels. Among these causes is hCG secretion by tumors. This is a report of a female with pancreatic cancer that presented for a Whipple procedure, who on routine pregnancy testing was found to have an elevated hCG level. This unexpected result led to significant delay and undue stress for the patient. After determining pregnancy was unlikely and multiple poorly differentiated metastatic masses were discovered, it was decided that the most likely cause of her hCG levels was cancer. Multiple cancers have been reported to secrete hCG, and more specifically $\beta$ hCG [1]. Studies of elevated hCG in pancreatic cancer patients report an incidence of $40 \%-56 \%$ [2,3]. Serum $\beta$ hCG testing done prior to the date of surgery (DOS) in cancer patients that are pre- or perimenopausal should be considered as it would allow time for a more definitive pregnancy evaluation to be performed.
\end{abstract}

Keywords: Pregnancy Test; Cancer, $\beta$ hCG

\section{Introduction}

In 2012 the American Society of Anesthesiologists (ASA) task force on preanesthesia evaluation stated "pregnancy testing may be offered to female patients of childbearing age and for whom the result would alter the patient's management" [4]. It is not definitive if anesthesia is harmful to a pregnancy; however, the general consensus is that surgery should be delayed until after first trimester if not until after delivery [5]. Thus, the task force allows physicians and patients to make decisions on preoperative testing on an individual basis. At our institution, all females of childbearing age have urine human chorionic gonadotrophin (hCG) levels checked on the date of surgery (DOS).

Studies examining unexpected positive pregnancy tests during preoperative testing demonstrated a rate of 0.15 to $2.2 \%$ [6-8]. Kahn et al. reported, in a retrospective analysis, a false positive pregnancy rate of $0.15 \%$ (4/2588 patients) [8]. While a prospective study of 315 women who had serum $\beta$ hCG testing prior to surgery showed an unexpected positive result of $2.2 \%$ [6]. Although the rate is variable, unexpected and false positive pregnancy tests do occur and further investigation is required. Proper interpretation can minimize the delay of necessary surgeries and emotional distress for patients.
There is little literature in anesthesia journals regarding the interpretation of pregnancy testing. The following is a case report that demonstrates the potential inaccuracy of pregnancy tests as hCG levels can be elevated for reasons other than pregnancy such as advanced cancer or perimenopause.

\section{Case Report}

A 51-year-old female was admitted for an elective Whipple procedure. She initially presented with darkening urine and abdominal pain. She was noted to have elevated liver function tests, bilirubin level, and carbohydrate antigen (CA) 19-9 level (130.3). An endoscopic retrograde cholangiopancreatography (ERCP) with bile duct brushings revealed moderately differentiated adenocarcinoma. A common bile duct stent was placed. A computed tomography (CT) scan noted a pancreatic head mass, suspicious peripancreatic and proximal para-aortic nodes. There was no evidence of metastasis.

The patient presented for a Whipple procedure. The DOS urine hCG test result was positive so a serum sample was sent. The patient revealed that she had irregular menstrual cycle for the past few years and her last menstrual period was 2 months prior. She also explained she has not been sexually active for years. She felt the preg- 
nancy test results were inaccurate and wished to proceed with surgery. After consulting with legal advisors of the institute it was decided that, with an informed consent, surgery and anesthesia services could proceed. After discussion with the patient, informed consents for anesthesia and surgery were signed.

The qualitative urine pregnancy test used was the Quidel QuickVue +, One-Step hCG Combo test. The test is considered positive if $\mathrm{hCG}>20 \mathrm{mIU} / \mathrm{mL}$. In normal pregnancy, hCG levels in urine and serum range from 5 $50 \mathrm{mIU} / \mathrm{mL}(1 \mathrm{IU} / \mathrm{L}=2.93 \mathrm{pmol} / \mathrm{L})$ as early as 1 week post conception. The quantitative serum test used was by TOSOH: ST AIA-PACK. Serum $\beta$ hCG concentrations $>$ $5.0 \mathrm{mIU} / \mathrm{mL}$ are considered positive. There is a $0.3 \%$ cross reactivity to $\mathrm{hFSH}$. The calibrators for both assays have been standardized against World Health Organization 3rd International Standard for Chorionic Gonadotrophin with ampules coded 75/537 (1975).

In the operating room, general anesthesia was induced and the trachea was intubated. After surgery commenced, serum hCG results returned with a quantitative value of $334 \mathrm{mIU} / \mathrm{mL}$.

During surgical exploration liver nodules were noted. A gynecology/oncology specialist was called to evaluate the peritoneal cavity and found no evidence a primary gynecologic tumor or pregnancy. A biopsy of a liver lesion revealed a highly undifferentiated spindle cell cancer presumably from metastasis. Interestingly, the liver lesions were less differentiated than the pancreatic lesion. The surgery was abandoned given the new diagnosis of widely metastatic stage IV pancreatic cancer. Emergence and extubation were uneventful. The patient was informed of her diagnosis and chemotherapy was pursued with an oncologist.

\section{Discussion}

This case of a false positive pregnancy test most likely due to malignancy is one of the first in anesthesia literature to emphasize the importance of understanding and interpreting preoperative pregnancy tests. The patient presented had two reasons for developing elevated hCG levels, (1) perimenopausal increase and (2) secretion via a poorly differentiated tumor.

$\beta$ hCG is primarily produced by syncytiotrophoblasts of the placenta to maintain progesterone secretion, which in turn maintains a healthy uterus for pregnancy [9]. The $\beta$ subunit of the heterodimeric hCG glycoprotein hormone determines the compounds biological activity and is target receptor specific [10,11]. Only $10 \%-20 \%$ of $\beta$ $\mathrm{hCG}$ is found in unbound form [12]. The $\alpha$ subunit of an hCG molecule is encoded by 1 gene, while the $\beta$ subunit is encoded by 4 nonalleic genes and additional allelic genes $[10,11]$. In addition, six out of eight glycosylation sites on hCG appear on the $\beta$ subunit, lending it further heterogeneity in biological activity [13]. Hyperglycosylated hCG (H hCG) plays an essential role in angiogenesis, immunosuppression, and growth during pregnancy. Studies have already demonstrated measuring $\mathrm{H}$ hCG is useful in diagnosing gestational trophoblastic neoplasia (GTN) [14-16]. When hCG is excreted into urine, it is degraded to "nicked" forms $[17,18]$.

In the presented case, the patient was perimenopausal with an aggressive and retrodifferentiated metastatic cancer. Although menopause could still in part have been a cause of elevated $\beta$ hCG levels, the anaplastic masses and the high level of the serum $\beta$ hCG make it most likely that the cancer was the source.

Most commonly, hCG is known to be produced by GTN. However, trophoblastic retrodifferentiation in nongestational neoplasms can also cause elevated hCG levels $[1,19]$. It is this retrodifferentiation into an invasive and highly proliferative tissue type that likely resulted in a moderately differentiated primary tumor transforming into the poorly differentiated lesions that produced $\mathrm{hCG}$ detected in the presented patient.

The overall incidence of elevated hCG and $\beta$ hCG levels in the serum of those with gastrointestinal (GI) cancers measured by radioimmunoassays was $21 \%$ [20]. Higher rates have been reported for pancreatic cancer patients. Studies using $\beta$ hCG serum levels and immunohistochemical staining of tissue have demonstrated that $\beta$ $\mathrm{hCG}$ is produced in $40 \%-56 \%$ in pancreatic cancers $[2,3]$. Syrigos et al. examined serum concentrations of $\beta$ hCG in randomly selected exocrine pancreatic adenocarcinoma patients. Forty-two percent (15/36) of patients with pancreatic carcinoma, 8\% (1/12) of chronic pan- creatitis patients, and $0 / 21$ normal individuals had de- tectable serum $\beta$ hCG concentrations [2]. The production of $\beta$ hCG was correlated with a more aggressive clinical course and a poorer prognosis with no systematic differences in the surgical procedures $(p=0.01)$ [2]. Alfthan et al. found an even higher occurrence of elevated hCG levels. Seventy-two percent (21/29 pancreatic cancer patients) had serum $\beta$ hCG levels $>1.7$ $\mathrm{pmol} / \mathrm{L}$ using immunofluorometric assays in the serum and $55 \%$ had elevated hCG $\beta$ cf in the urine [12]. Sources have shown that the majority of pancreatic cancers predominantly produce free $\beta \mathrm{hCG}[12,21]$. Reported rates of $\beta$ hCG production by malignancies are extremely variable depending on study design and assay. The frequency of elevated $\beta$ hCG in biliary (56\%) and gastric (41\%) cancers was similar to that of pancreatic cancers [9]. High rates were also reported with testicular[22,23] and gynecologic cancer [24]. Lower rates were reported in other GI cancers $[25,26]$ and urologic cancers $[1,27$, 28]. A large number of metastatic breast cancer patients were found express elevated levels (48.5\%) [29], although confounding factors may exist [1]. Head and neck can- 
cers [30], lung cancers [31-33] and lymphomas [1] are less likely to express $\beta$ hCG. Although studies have variable definitions of elevated $\beta$ hCG levels, levels can become high enough to cause qualitiative serum $\beta$ hCG tests to read positive $(5.0 \mathrm{mIU} / \mathrm{mL}=14.65 \mathrm{pmol} / \mathrm{L})$. Large scale studies to determine the frequency of tumors producing $\beta$ hCG levels high enough to cause positive pregnancy tests have not yet been conducted.

Low concentrations of hCG and its subunits can be secreted by the pituitary gland [34]. There is an increase in pituitary secretion in menopausal women that is accompanied by elevated luteinizing hormone (LH) and follicle-stimulating hormone (FSH) levels [35,36]. Cole et al. reported on 28 women with elevated serum hCG levels that were attributed to their menopausal status. The mean hCG level was $9.5 \pm 6.5 \mathrm{mIU} / \mathrm{mL}$ [37]. None of the patients had elevated $\mathrm{H}$ hCG or free $\beta$ subunit levels, which are the forms that are more commonly produced by cancers $[2,38]$. Treatment with hormone-replacement therapy can suppress pituitary secretion over a period of 1 to 2 weeks and thereby allow detection of ectopic production (by cancerous cells) of hCG in menopausal patients $[39,40]$.

Given that malignancies can cause elevated hCG levels that are unrelated to pregnancy, physicians should consider hCG testing prior to DOS in those of appropriate age. It would be beneficial to check levels during initial office visits to establish a baseline value. If initial values are elevated, a further work-up should be pursued by an obstetrician. Besides a history and physical exam, evaluation may include imaging to detect new metastasis, LH and FSH levels, ability to suppress hCG levels with hormone replacement, or an ultrasound [34]. Transvaginal ultrasounds can detect gestational sac as early as 3 weeks after conception or when the serum $\beta$ hCG is greater than $1500 \mathrm{mIU} / \mathrm{mL}$ [41]. In the case of an initially elevated hCG level, a prescheduled ultrasound should considered for the DOS (Figure 1). Repeating an hCG levels on the DOS has limited utility as an increase of hCG due to tumor growth can mimic hCG doubling that typically occurs every 48 hours in early pregnancy $[42,43]$. In patients with initially normal hCG levels, a DOS positive pregnancy test would most likely indicate a pregnancy. In cases of suspected pregnancy, the patient's decision to proceed with surgery should take into account the nature of the cancer, risks to pregnancy/fetus due to surgery and anesthesia, and the patient's desire to have a child. Hospitals and physicians should consider these scenarios when instituting policies on pregnancy testing in those with malignancies.

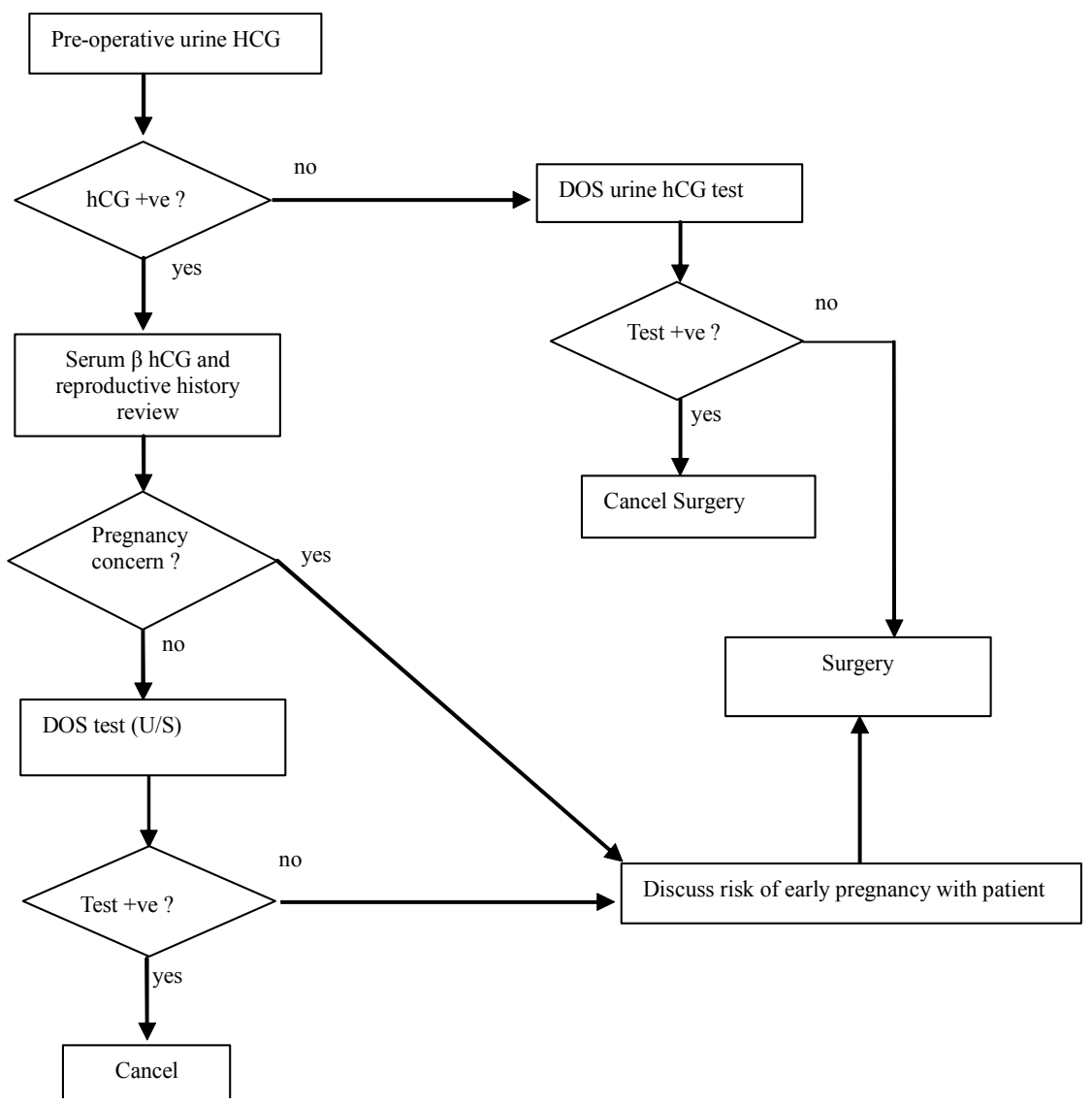

Figure 1. Evaluation for pregnancy in pre- and perimenoupasal women scheduled for oncologic surgeries. 
In this case, an unexpected positive urine and serum hCG level resulted in unnecessary delays and patient anxiety. With the knowledge that multiple causes other than true pregnancy exist for an elevated hCG level, performing hCG testing prior to DOS on appropriate patients would allow time for evaluation of unexpected results. Hospitals should consider this information when instituting pregnancy testing policies.

\section{REFERENCES}

[1] U. H. Stenman, H. Alfthan and K. Hotakainen, "Human Chorionic Gonadotropin in Cancer," Clinical Biochemistry, Vol. 37, No. 7, 2004, pp. 549-561. doi:10.1016/j.clinbiochem.2004.05.008

[2] K. N. Syrigos, I. Fyssas, M. M. Konstandoulakis, K. J. Harrington, S. Papadopoulos, N. Milingos, P. Peveretos and B. C. Golematis, "Beta Human Chorionic Gonadotropin Concentrations in Serum of Patients with Pancreatic Adenocarcinoma," Gut, Vol. 42, No. 1, 1998, pp. 8891. doi:10.1136/gut.42.1.88

[3] J. Louhimo, S. Nordling, H. Alfthan, K. von Buguslawski, U. H. Stenman and C. Haglund, "Specific Staining of Human Chorionic Gonadotropin Beta in Benign and Malignant Gastrointestinal Tissues with Monoclonal Antibodies," Histopathology, Vol. 38, No. 5, 2001, pp. 418424. doi:10.1046/j.1365-2559.2001.01106.x

[4] Practice Advisory for Preanesthesia Evaluation, "An Updated Report by the American Society of Anesthesiologists Task Force on Preanesthesia Evaluation," Anesthesiology, Vol. 116, No. 3, 2012, pp. 1-17.

[5] S. Manley, G. Kelaita, N. J. Joseph, M. R. Salem and H. J. Heyman, "Preoperative Pregnancy Testing in Ambulatory Surgery," Anesthesiology, Vol. 83, No. 4, 1995, pp. 690693. doi:10.1097/00000542-199510000-00007

[6] R. S. Twersky and G. Singleton, "Preoperative Pregnancy Testing: 'Justice and Testing for All'," Anesthesia \& Anal-gesia, Vol. 83, No. 2, 1996, pp. 438-439. doi:10.1213/00000539-199608000-00059

[7] M. Wheeler and C. J. Cote, "Preoperative Pregnancy Testing in a Tertiary Care Children's Hospital: A MedicoLegal Conundrum," Journal of Clinical Anesthesia, Vol. 11, No. 1, 1999, pp. 56-63. doi:10.1016/S0952-8180(98)00136-6

[8] R. L. Kahn, M. A. Stanton, S. Tong-Ngork, G. A. Liguori, C. R. Edmonds and D. S. Levine, "One-Year Experience with Day-of-Surgery Pregnancy Testing before Elective Orthopedic Procedures," Anesthesia \& Analgesia, Vol. 106, No. 4, 2008, pp. 1127-1131. doi:10.1213/ane.0b013e31816788df

[9] J. Louhimo, P. Finne, H. Alfthan, U. H. Stenman and C. Haglund, "Combination of HCG Beta, CA 19-9 and CEA with Logistic Regression Improves Accuracy in Gastrointestinal Malignancies," Anticancer Research, Vol. 22, No. 3, 2002, pp. 1759-1764.

[10] S. Birken, G. Kovalevskaya and J. O'Connor, "Immunochemical Measurement of Early Pregnancy Isoforms of HCG: Potential Applications to Fertility Research, Pre- natal Diagnosis, and Cancer," Archives of Medical Research, Vol. 32, No. 6, 2001, pp. 635-643.

doi:10.1016/S0188-4409(01)00329-0

[11] D. Bellet, V. Lazar and I. Bieche, "Malignant Transformation of Nontrophoblastic Cells Is Associated with the Expression of Chorionic Gonadotropin Beta Genes Normally Transcribed in Trophoblastic Cells," Cancer Research, Vol. 57, No. 3, 1997, pp. 516-523.

[12] H. Alfthan, C. Haglund, P. Roberts and U. H. Stenman, "Elevation of Free Beta Subunit of Human Choriogonadotropin and a Core Beta Fragment of Human Choriogonadotropin in the Serum and Urine of Patients with Malignant Pancreatic and Biliary Disease," Cancer Research, Vol. 52, No. 17, 1992, pp. 4628-4633.

[13] U. H. Stenman, L. Unkila-Kallio, J. Korhonen and H. Alfthan, "Immunoprocedures for Detecting Human Chorionic Gonadotropin: Clinical Aspects and Doping Control," Clinical Chemistry, Vol. 43, No. 3, 1997, pp. 1293 1298.

[14] L. A. Cole, "Hyperglycosylated hCG, a Review," Placenta, Vol. 31, No. 8, 2010, pp. 653-664. doi:10.1016/j.placenta.2010.06.005

[15] L. A. Cole and S. Butler, "Hyperglycosylated hCG, hCG $\beta$ and Hyperglycosylated $\mathrm{hCG} \beta$ : Interchangeable Cancer Promoters," Molecular and Cellular Endocrinology, Vol. 349, No. 2, 2012, pp. 232-238. doi:10.1016/j.mce.2011.10.029

[16] L. A. Cole, S. A. Butler, S. A. Khanlian, A. Giddings, C. Y. Muller, M. J. Seckl and E. I. Kohorn, "Gestational Trophoblastic Diseases: 2. Hyperglycosylated hCG as a Reliable Marker of Active Neoplasia," Gynecologic Oncology, Vol. 102, No. 2, 2006, pp. 151-159. doi:10.1016/j.ygyno.2005.12.045

[17] D. L. Matthies and E. Diczfalusy, "Relationships between Physico-Chemical, Immunological and Biological Properties of Human Chorionic Gonadotrophin. I. Properties of Human Chorionic Gonadotrophin as Found in Tissues and Body Fluids," Acta Endocrinology, Vol. 67, No. 3, 1971, pp. 434-444.

[18] P. D. Papapetrou, N. P. Sakarelou, H. Braouzi and P. Fessas, "Ectopic Production of Human Chorionic Gonadotropin (hCG) by Neoplasms: The Value of Measurements of Immunoreactive hCG in the Urine as a Screening Procedure," Cancer, Vol. 45, No. 10, 1980, pp. 25832592. doi:10.1002/1097-0142(19800515)45:10<2583::AID-CN CR2820451018>3.0.CO;2-W

[19] S. Strickland and W. G. Richards, "Invasion of the Trophoblast Cell," Cell, Vol. 71, 1992, pp. 355-357. doi:10.1016/0092-8674(92)90503-5

[20] R. O. Hussa, "The Clinical Marker hCG," Praeger, New York, 1987.

[21] A. S. Duffield, P. Jarrar, C. Shum, N. Ahuja, C. J. Yeo and L. J. Sokoll, "Retroperitoneal Masses with Associated Human Chorionic Gonadotropin Production: Report of Two Cases," Clinica Chimica Acta, Vol. 395, No. 1-2, 2008, pp. 166-169. doi:10.1016/j.cca.2008.04.030

[22] S. Hoshi, K. Suzuki, S. Ishidoya, C. Ohyama, M. Sato, T. Namima, S. Saito and S. Orikasa, "Significance of Si- 
multaneous Determination of Serum Human Chorionic Gonadotropin (hCG) and hCG-Beta in Testicular Tumor Patients," International Journal of Urology, Vol. 7, No. 6, 2007, pp. 218-223.

doi:10.1046/j.1442-2042.2000.00181.x

[23] I. Marcillac, F. Troalen, J. M. Bidart, P. Ghillani, V. Ribrag, B. Escudier, B. Malassagne, J. P. Dorz, C. Lhomme, P. Rougier, et al., "Free Human Chorionic Gonadotropin Beta Subunit in Gonadal and Nongonadal Neoplasms," Cancer Research, Vol. 52, No. 14, 1992, pp. 3901-3907.

[24] C. Y. Muller and L. A. Cole, "The Quagmire of hCG and hCG Testing in Gynecologic Oncology," Gynecologic Oncology, Vol. 112, No. 3, 2009, pp. 663-672. doi:10.1016/j.ygyno.2008.09.030

[25] G. D. Braunstein, J. L. Vaitukaitis, P. P. Carbone and G. T. Ross, "Ectopic Production of Human Chorionic Gonadotrophin by Neoplasms," Annals of Internal Medicine, Vol. 78, No. 1, 1973, pp. 39-45.

[26] M. Lundin, S. Nordling, J. Lundin, H. Alfthan, U. H. Stenman and C. Haglund, "Tissue Expression of Human Chorionic Gonadotropin Beta Predicts Outcome in Colorectal Cancer: A Comparison with Serum Expression," International Journal of Cancer, Vol. 95, No. 1, 2001, pp. $18-22$.

doi:10.1002/1097-0215(20010120)95:1<18::AID-IJC100 3>3.0.CO;2-5

[27] K. Hotakainen, B. Ljungberg, A. Paju, T. Rasmuson, H. Alfthan and U. H. Stenman, "The Free Beta-Subunit of Human Chorionic Gonadotropin as a Prognostic Factor in Renal Cell Carcinoma," British Journal of Cancer, Vol. 86, No. 2, 2002, pp. 185-189. doi:10.1038/sj.bjc.6600050

[28] V. M. Shah, J. Newman, J. Crocker, G. N. Antonakopoulos, C. R. Chapple and M. J. Collard, "Production of Beta-Human Chorionic Gonadotropin by Prostatic Adenocarcinoma and Transitional Cell Carcinoma of the Upper Urinary Tract," British Journal of Experimental Pathology, Vol. 68, No. 6, 1987, pp. 871-878.

[29] D. C. Tormey, T. P. Waalkes and R. M. Simon, "Biological Markers in Breast Carcinoma. II. Clinical Correlations with Human Chorionic Gonadotrophin," Cancer, Vol. 39, No. 6, 1997, pp. 2391-2396.

doi:10.1002/1097-0142(197706)39:6<2391::AID-CNCR2 820390613>3.0.CO;2-7

[30] J. Hedstrom, R. Grenman, H. Ramsay, P. Finne, J. Lundin, C. Haglund, H. Alfthan and U. H. Stenman, "Concentration of Free hCG Beta Subunit in Serum as a Prognostic Marker for Squamous-Cell Carcinoma of the Oral Cavity and Oropharynx," International Journal of Cancer, Vol. 84, No. 5, 1999, pp. 525-528. doi:10.1002/(SICI)1097-0215(19991022)84:5<525::AIDIJC14>3.0.CO;2-Q

[31] R. W. Burt, J. G. Ratcliffe, B. H. Stack, J. Cuthbert, R. S. Kennedy, C. S. Corker, P. Franchimont, W. G. Spilg and W. H. Stimson, "Serum Biochemical Markers in Lung Cancer," British Journal of Cancer, Vol. 37, 1978, pp. 714-717. doi:10.1038/bjc. 1978.108

[32] M. Szturmowicz, E. Wiatr, A. Sakowicz, J. Slodkowska, K. Roszkowski, S. Filipecki and E. Rowinska-Zakrewska, "The Role of Human Chorionic Gonadotropin Beta Subunit Elevation in Small-Cell Lung Cancer Patients," Jour- nal of Cancer Research and Clinical Oncology, Vol. 121, No. 5, 1995, pp. 309-312. doi:10.1007/BF01209599

[33] M. Szturmowicz, J. Slodkowska, J. Zych, P. Rudzinski, A. Sakowicz and E. Rowinska-Zakrzewska, "Frequency and Clinical Significance of Beta-Subunit Human Chorionic Gonadotropin Expression in Non-Small Cell Lung Cancer Patients," Tumour Biology, Vol. 20, No. 2, 1999, pp. 99104. doi: $10.1159 / 000030052$

[34] C. Palmieri, T. Dhillon, R. A. Fisher, A.-M. Yound, D. Short, H. Mitchell, C. Aghajanian, P. M. Savage, E. S. Newlands, B. W. Hancock and M. J. Seckl, "Management and Outcome of Healthy Women with a Persistently Increased Beta-hCG," Gynecologic Oncology, Vol. 106, 2007, pp. 35-43. doi:10.1016/j.ygyno.2007.01.053

[35] U. H. Stenman, H. Alfthan, T. Ranta, E. Vartiainen, J. Jalkanen and M. Seppälä, "Serum Levels of Human Chorionic Gonadotropin in Nonpregnant Women and Men Are Modulated by Gonadotropin-Releasing Hormone and Sex Steroids," The Journal of Clinical Endocrinology \& Metabolism, Vol. 64, No. 4, 1987, pp. 730736. doi:10.1210/jcem-64-4-730

[36] E. Daiter, G. D. Braunstein, P. J. Snyder, C. Coutifaris, L. Mastroianni, S. N. Pavlou and J. F. Strauss, "Gonadotropin-Releasing Hormone-Dependent Chorionic Gonadotropin Secretion in a Menopausal Woman," The Journal of Clinical Endocrinology \& Metabolism, Vol. 78, No. 6, 1994, pp. 1293-1297. doi:10.1210/jc.78.6.1293

[37] L. A. Cole, Y. Sasaki and C. Y. Muller, "Normal Production of Human Chorionic Gonadotropin in Menopause," New England Journal of Medicine, Vol. 356, No. 11, 2007, pp. 1184-1186. doi:10.1056/NEJMc066500

[38] L. A. Cole, S. A. Khanlian, C. Y. Muller, A. Giddings, E. I. Kohorn and R. Berkowitz, "Gestational Trophoblastic Diseases. 3. Human Chorionic Gonadotropin-Free $\beta$-Subunit, a Reliable Marker of Placental Site Trophoblastic Tumors," Gynecologic Oncology, Vol. 102, No. 2, 2006, pp. 160-164. doi:10.1016/j.ygyno.2005.12.046

[39] P. D. Papapetrou and N. I. Anagnostopoulos, "A Gonadotropin and Alpha-Subunit Suppression Test for the Assessment of the Ectopic Production of Human Chorionic Gonadotropin and Its Subunits after the Menopause," The Journal of Clinical Endocrinology \& Metabolism, Vol. 60 , No. 6, 1985, pp. 1187-1195. doi:10.1210/jcem-60-6-1187

[40] W. J. Catalona, J. L. Vaitukaitis and W. R. Fair, "Falsely Positive Specific Human Chorionic Gonadotropin Assays in Patients with Testicular Tumors: Conversion to Negative with Testosterone Administration," Journal of Urology, Vol. 122, No. 1, 1979, pp. 126-128.

[41] D. A. Nyberg, R. A. Filly, B. S. Mahony, S. Monroe, F. C. Laing and R. B. Jeffrey, "Early Gestation: Correlation of HCG Levels and Sonographic Identification," American Journal of Roentgenology, Vol. 144, No. 5, 1985, pp. 951-954.

[42] K. D. Bagshawe, "Choriocarcinoma. A Model for Tumour Markers," Acta Oncology, Vol. 31, 1992, pp. 99106. doi:10.3109/02841869209088275

[43] T. Chard, "Pregnancy Tests: A Review," Human Reproduction, Vol. 7, No. 5, 1992, pp. 701-710. 